\title{
Speaking Mennonite at School: A Narrative Analysis of the Role of Language in Immigrant Educational Experiences
}

\author{
CHRISTINE KAMPEN ROBINSON \\ University of Waterloo
}

\section{Abstract}

This paper examines the ways in which 1.5-generation immigrant mothers from a marginalized minority group (Low German-speaking Mennonites from Mexico) construct school experiences in relation to language. Starting from the perspective of identity as being constructed in language, analysis of audio-recorded interviews and focus group discussions collected during 18 months of ethnographic fieldwork demonstrates a connection and an inherent tension between the ways in which participants construct their own experiences and how they construct their children's experiences. Results illustrate the impact of language and literacy on their identity constructions, the use of language as an act of civic engagement, and how the agentive capacity demonstrated through these constructions both engages with and contests broader social processes.

\section{Keywords}

Identity, Low German, migration, multilingualism, positioning theory, public school

\section{Introduction}

Civic engagement can be seen as citizens working together to make a change or a difference in their community (Delli, 2016), and includes communities working together in both political and non-political actions (Bennett, Cordner, Taylor Klein, Savell, et al., 2013). In this paper, I investigate how a 1.5 generation woman (Rumbaut, 2002) from a specific linguistic community (Low German-speaking Mennonites (LGMs) returning to Canada from Mexico) works to address issues of public concern in and through her talk about her experiences as a student and as a mother or children enrolled in a public school in Canada. In doing so, I draw attention to the centrality of language in the shifting in agentive capacity for migrants. I also raise the question of how children use their home language in a public school space may be considered an act of civic engagement. I conclude with specific recommendations for agencies and institutions engaged with this specific community and with other similarly marginalized communities.

\section{Research Context}

Low-German speaking Mennonites (LGMs) are a unique cultural group in Canada. Of European origin, this group migrated from Russia to Canada in the 1870s, establishing villages and colonies in Manitoba and Saskatchewan. These families came to Canada following extensive religious persecution, first in Reformation-era Europe and then in Russia. The primary points of theological contention at the time of immigration were adult rather than infant baptism, as well as a staunch belief in pacifism. Both of these central tenets were extremely counter-cultural at the time, resulting in widespread persecution of Anabaptists on charges of heresy (Smith, 1981). 
As argued by Loewen (2013) and Good Gingrich (2016), much of LGM experience is characterized by a desire to remain "in the world, but not of the world" (John 17:16), and the imperative not to "conform any longer to the pattern of this world" (Romans 12:2). In practice, this has meant dressing in a way that sets them apart from mainstream - full-length dresses and head coverings for women, and dark colours and clean shaves for men (cf. Bombardier, 2016). It has also meant using a language different from the majority (Low German, or Dietsch, specifically), and educating their children in their own schools, where they have traditionally had control over language and curriculum content.

After the School Attendance Act was enacted in Manitoba and Saskatchewan in the early 1920s, affecting LGMs' control over their parochial schools, a group of approximately 5000 LGMs immigrated to Mexico to establish colonies and villages there (Krahn \& Sawatzky, 1990). LGMs saw the encroachment of the provincial government on their schools as curtailing their religious freedoms. The school system they had developed was seen as an extension of the Old Colony Church. Although they explored a number of different options for immigration, they settled on Mexico because they were promised the same religious freedoms they had initially experienced in Canada (Loewen, 2013).

By the 1950s, however, economic hardship in Mexico, combined with the Canadian citizenship that a majority of the LGMs held, brought many LGMs back to Canada. While at first, they returned as seasonal workers, eventually many LGMs elected to stay in Canada, to settle and raise families, integrating themselves (some to greater, some to lesser extents) into wider Canadian culture (Steiner, 2015). LGMs' complicated migration history is manifested most clearly in their language (Dietsch), which contains elements of Dutch, Prussian, Mennonite High German ${ }^{1}$, Russian, English, and Spanish, embedded in a Germanic structure, as these are the languages with which the LGMs have come into contact throughout their migration history (Cox, 2013).

According to Mennonite Central Committee Ontario, south-western Ontario is home to approximately 40,000 LGMs (the exact number is unknown because so many families still migrate back and forth yearly) (Steiner, 2015). Service providers working with LGMs ${ }^{2}$ often talk about how difficult it is for LGM families to acculturate to life in Canada, especially when they first arrive from Mexico. In part, this is due to the fact that the segregated lives they lived in Mexico cannot be replicated in the Canadian contextthere is too much space between community members and too much interaction with the wider Canadian. It is also due, in a large part, to the differences in approaches to and purposes for education in the Old Colony context as compared with the Canadian context. Although parochial schools exist, many parents elect to send their children to public

\footnotetext{
${ }^{1}$ I use the term "High German" rather than "Standard German" to refer to the "prestige"-variety that LGMs come into contact with because it is their term, and has developed substantially differently from the standard variety spoken in Germany today (cf. Cox, 2013; Hedges, 1996). ${ }^{2}$ Low German-speaking Mennonites are often referred to in relation to the governing religious body they are associated with - the Old Colony Church. I have not done so here, because defining the group by their association with the church creates an unhelpful in-group/out-group categorization. Instead, I have elected to use the term "Low German-speaking Mennonite" or LGM, as this is in keeping with how the members of the group refer to themselves - as "Dietsch" (Low German for "German").
} 
school with secular Canadian peers (Sneath \& Fehr Kehler, 2016). In this way, LGMs' experiences of school and of life in Canada are significantly different than that of the generation born and raised in Mexico.

Adding to these differences and difficulties in terms of acculturation in Canada, LGMs are not the only kind of conservative Mennonite group in rural Ontario. Rural Canadian public schools must also contend with the challenges of multiple Mennonite factions in addition to the LGMs, including Conservative and David Martin Mennonites, for example. These different Mennonite groups speak different languages-Low German and Pennsylvania German, specifically, and in public schools, children actively use their languages to create in-group/out-group categorizations. The different languages are also often used to bully and ostracize other groups, sometimes leading to physical altercations, which have resulted in some schools banning languages other than English to be used in the classroom and on the playground. To this end, the language practices of LGM young people within schools must be seen as distinct acts of civic engagement.

LGMs present a particularly interesting and complicated portrait of a marginalized and yet agentive linguistic community. Elsewhere (Kampen Robinson, 2017), I have examined a variety of ways in which LGM women linguistically contest what constitutes the centre of Dietsch space in terms of what is seen as valued and legitimate). In this paper, I use an interactional sociolinguistic lens borrowing tools from Conversation Analysis (Gumperz, 1983; Schegloff, Jefferson, \& Sacks, 1977) and narrative analysis (Baynham, 2003; Georgakopoulou, 2007) to examinee one woman's $\left(\right.$ Neta's $\left.^{3}\right)$ narratives about her own and her children's school experiences. In doing so, I highlight the differences in the ways that Neta "positions" herself and her children (Harre and van Langenhove, 1991) in relation to the Canadian public school system and as language users. In recognizing the work that Neta does to assert herself and her children as capable language users, and to describe the difficulty of a school system that does not necessarily recognize children's linguistic competence, I illuminate how she raises issues of public concern and effectively addresses these issues, producing a new civic identity for herself and her children.

\section{Methodology}

This paper is based on eighteen months of ethnographic field work with a group of LGM mothers taking part in a Canadian Action Plan for Children (CAPC) program in the Waterloo Region ${ }^{4}$. These women were between the ages of 21-45, with children ranging in age from infants to seventeen years old. The majority immigrated to Canada from Mexico as children, and would be considered 1.5 generation (Rumbaut, 2002). The participants ranged from continuing to be very involved in the Old Colony Church to completely unaffiliated with it. All of the women in my study sent their children to the local public schools.

The data for this paper emerge from two semi-structured focus group discussions, which were conducted approximately one year apart. The first focus group discussion was held when I did not yet know the women in the group very well. The second focus

${ }^{3}$ To protect the privacy of my study participants, and in keeping with Ethics Clearance of the University of Waterloo, names and identifying details about my participants have been changed.

${ }^{4}$ This project has received full ethical clearance from the Office of Research Ethics at the University of Waterloo. 
group discussion was held just over a year later, when I had built relationships of trust with the majority of the women, and we had had the opportunity to have many informal conversations while cooking and laughing together. While the data for this paper come from the focus group discussions I hosted with the women, and focus on the stories of one woman in particular, they are supplemented by all of these conversations, as well as a series of four in-depth semi-structured individual interviews, and two recorded conversations of group meetings.

\section{Analysis: Neta}

The focus group discussions I conducted with the women were large. At first, participants were hesitant to participate because I was asking them about their language learning experiences and feelings about English and Low German, and these were not topics they talked about on a regular basis. Some women mentioned that they had never voiced the stories they were telling before, and had had no idea that others had experienced the same feelings of fear and frustration. Most of the women who came to Canada and were made to go to public school shared the feeling of being alone, carrying the weight of how sinful and wrong to be going to school in the first place. Since education that is different from the community norm is seen as inherently sinful, LGMs who elect to send their children to public school are caught in what Good Gingrich (2016) calls "a double bind." In other words, LGMs are caught between the pull of the expectations of their church community and the expectations of mainstream Canadian culture, a tension they must constantly negotiate.

When asked, the women told me that they had never talked about their feelings about their own school experiences because they had always supposed they were the only ones with these feelings. Neta and her sister were both part of the first focus group discussion. They have a close relationship, but even they had never talked about how the experiences they had had in school had felt.

The following excerpt-presented in Jeffersonian transcription, where a capital letter denotes louder speech-occurred midway through the second focus group discussion. The story Neta tells clearly impacted her as she repeated it in both focus group discussions, as well as her individual interview. Going to public school in Canada was complicated for her because in Mexico, she had already finished school. ${ }^{5}$ Being made to go back to school as a 14-year old felt like the worst kind of infantilizing to her. Her experience was further complicated by the fact that she spoke no English and there were no other LGMs her age at the school. At first, she reported that her teachers didn't know what to do with her and gave her paper and coloured pens to keep her busy. Being tasked with colouring during class time frustrated her as she was already considered a grown up in the Old Colony community.

Today, Neta is an active member of the Old Colony Church, and has worked tirelessly for change in the Sunday School curriculum to keep her children engaged. She values both the Old Colony Church, and her children's Canadian (English-language) education. Other speakers in this excerpt include Greta, who is no longer a member of the Old Colony Church, and who has taken a leadership role in the Community Action Plan

\footnotetext{
${ }^{5}$ It is common for LGM children attending the colony schools in Mexico to attend school until age 11 or 12 . After that, they are considered "grown up" and expected to contribute to life in the colony through farm and housework.
} 
for Children (CAPC) group programming. The other speaker is Julie, who leads the CAPC group, and has no Old Colony Church affiliation. Additional speakers are sisters Nellie and Bettie, one of whom remains active in the Old Colony Church while the other does not.

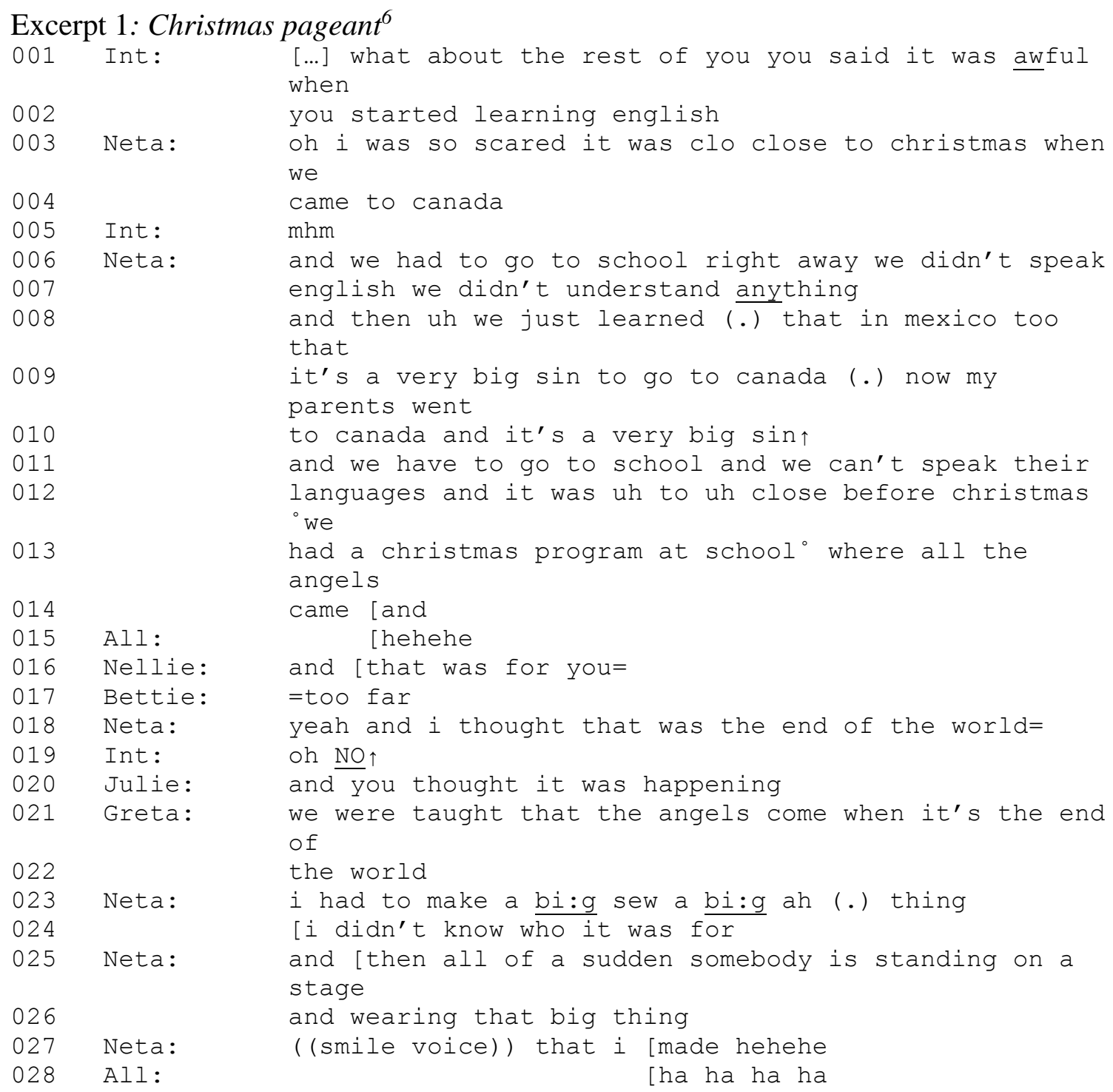

Neta relays some of the anxiety and confusion she experienced during her first few months in Canada. For Neta, learning English felt as though it was directly associated with the end of the world. The Christmas pageant was something she was made to participate in, though she did not understand what she was doing or why. In listening to this story, we can hear how Neta positions herself as voiceless participant in this narrative. For example, although she takes one action in the narrative ("sewing the big thing"), she otherwise positions herself as powerless to act against her fear (line 003:

${ }^{6}$ Transcripts follow Jeffersonian (2004) transcription conventions. 
"I was so scared") about the end of the world because she couldn't understand "their languages" (lines 011-012).

Neta never specifically defines who she means when referring to "they," but because she continued to use her comfortable language at home, it seems that this "they" refers to the public Canadian spaces she was made to inhabit. The use of this pronoun differentiation (we versus they), as well as other components of this excerpt (line 018; 021), also illustrate the religious tension Neta and her family experienced. They were already primed for worrying about the end of the world because the very fact they were in Canada at all was "a very big sin" — a fact which Neta repeats for emphasis (lines 009010), and which colours the whole narrative. She experienced distress when she realized that she had actively contributed to hastening the end of the world.

Another consideration is the centrality of the value of truthfulness in the LGM community. My participants explained to me off tape that dressing up to pretend to be something you aren't is considered lying, and therefore sinful and non-desirable. Pretending is discouraged in play, and also discouraged in the types of texts or stories children encounter. There should be only one version of the world - the one that is real and true. With this in mind, one of the primary reasons for Neta's terror is the fact that she has never been exposed to people actively pretending to be something they couldn't possibly be (angels). Since she had no frame of reference for understanding people playing pretend, she concludes that they must really be angels, and therefore she has contributed to bringing the end of the word.

During the first focus group discussion, Neta told a second story in relation to learning English. This story was about a field trip she took with her class to Niagara Falls, the spring after she came to Canada. There are two important co-constructors in this story who were present during the first focus group discussion who were not present for the second. The first co-constructor for Neta's narrative is her sister, Eva, who, like Neta, remains a part of the Old Colony Church, and was also connected to the CAPC group before she and her family moved away. She happened to be visiting around the time I wanted to conduct the first focus group discussion, so Neta invited her to come. Her presence is important because she experienced similar, and sometimes even the same events, which they then co-construct, correct and reshape in their retelling. Although Eva doesn't speak much during the following excerpt, her presence alone is important because of her involvement in Neta's experiences.

The second person who is a significant co-constructor in Neta's story is Gina, who was present for the first focus group discussion, but not for the second. Gina was the only non-LGM member of the group who attended regularly. While she was connected to Mennonites through part of her family's Swiss Mennonite background, she knew very little about the cultural or religious context that LGM women live with, and to my knowledge had never really asked very many questions about the context, despite knowing many of the women for a number of years. I include this second excerpt because it demonstrates the different way Neta positions herself in relation to other LGM women, and especially in relation to non-LGM individuals, like Gina. Both Neta and Greta engage with this lack of understanding of context by adding different levels of evaluation in the co-construction of the narrative, because they feel they have to explain more details. 
At the time of the first focus group discussion, the group was unclear about how much I knew about the LGM context, and it appeared that the participants hadn't decided what to make of me yet, so it is likely that the explanations and evaluations are just as much for my benefit as for Gina's. These evaluations are less directed at Julie and Rita (the non-LGM group facilitators), because all of the regular attenders had already developed relationships of trust with those two women that they hadn't developed yet with me or Gina at the time of the first focus group discussion.

The following story, told in the first focus group discussion, followed the initial telling of the Christmas pageant story, which Neta retold in the second focus group interview, as portrayed in Excerpt 1. The primary speakers are Neta herself, Greta, Irma, and Gina. Both Greta and Irma are no longer a part of the Old Colony Church. This story is significant because of the layers of agentive capacity it demonstrates. On the one hand, Neta constructs herself as having very little agentive capacity in the story, on the other, in the telling of the story itself, Neta constructs herself as having agentive capacityrejecting other positioning that disempowers her.

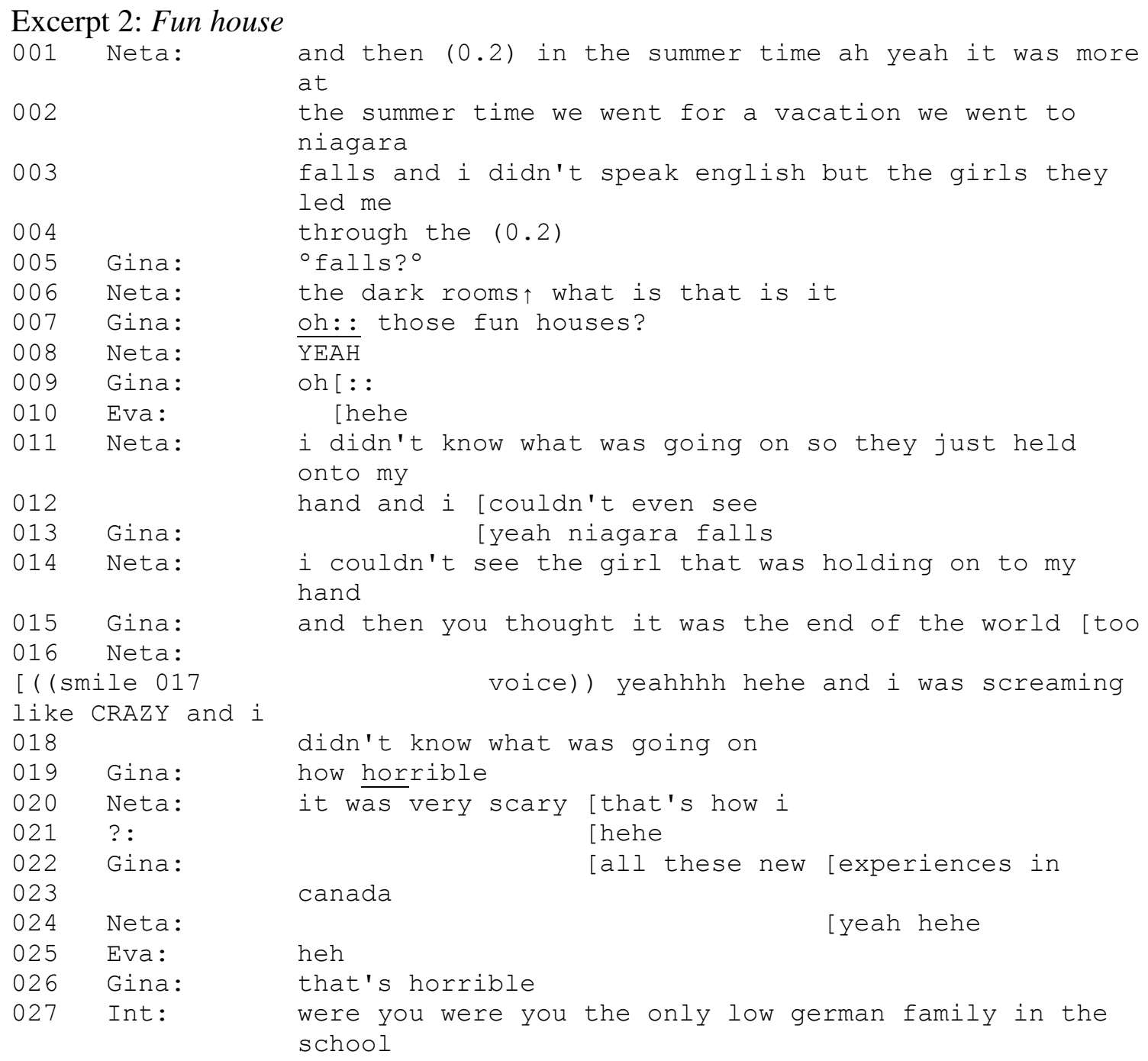


The "small story" (Georgakopoulou, 2007) about the funhouse is metaphorically significant to Neta's construction of her English language learning experiences in a number of ways. This story echoes the voicelessness and fear of the Christmas pageant story. Although Neta vocalizes the fear in this story (line 17: I was screaming like CRAZY), she doesn't have any words, only the screaming to express her fear. Similar to the Christmas pageant story, there were no explanations for what happened to her, because Neta's Canadian peers do not speak Low German and could not tell her what is going on. In this story, however, the terror is compounded by the fact that Neta "[can't] even see" (line 012). There are similar complications as the Christmas pageant story, since funhouses are filled with illusions and things that are not "real," in the way that Neta would have been used to.

A significant difference in the funhouse story as compared to the Christmas pageant story, is the presence of other people. In the Christmas pageant story, Neta describes herself as alone with her terror-there are people on the stage wearing the clothes that she made, but she does not talk about those she would have been watching the pageant with. In the story, she was alone in the audience, alone witnessing the end of the world, separated from any other people. In the funhouse story, however, Neta was not alone. Although there was no explanation for what was happening to her, and she was similarly terrified, there was a girl, "holding on to [her] hand," something Neta repeats twice (line 011-012, 014).

Another distinction between the two stories is the different reactions of the group. In Excerpt 1, where the majority of the listeners are also LGMs who have had similar experiences where they were lost because they couldn't speak English, the coconstruction of that story is a significant amount of group laughter, especially when Neta expresses how terrified she was during the event. In this excerpt, laughter functions as a group constituting mechanism, reinforcing the shared experience Neta describes. Specifically, laughter functions as an expression of solidarity-while the other women may not have experienced the same exact story, they have their own stories about attending school in Canada that were scary and made them feel foolish. The laughter is a comment on similarity of experience, and a way of subverting the feelings of powerlessness associated with this and similar stories. They are choosing to co-construct this narrative and connect their own experiences to this one. In Excerpt 2, on the other hand, the group does not have the same opportunity to co-construct and position themselves in an empowering way, because Gina continuously comments on "how horrible" things must have been for Neta. Although Neta and the others laugh in this excerpt as well (lines 010, 016, 024), Gina repeats her assessment of the story (lines 019, 026), and never joins in the laughter herself.

Neta's school experiences were not positive, in part because of her lack of agency. The fact that her English language proficiency was not adequate for her to grasp what was happening around her was complicated by the fact that she was experiencing culture shock and a significant amount of guilt from her socialization in Mexico. This in turn was coupled with the fact that she was being made to attend school after she had already finished school in Mexico, and the embarrassment of being made to feel like a small child again. Taken together, these factors underscore her position of powerlessness in both stories. 


\section{Analysis: Neta's Children}

Neta frequently talked about learning English, and even making sense of broader Canadian culture with which she came into contact in public spaces like the schools she attended being a struggle for her. The way she presents her own children's experiences in the Canadian school system is quite different however. The following excerpt is a return to an earlier discussion about languages the children speak, but this time in relation to official school policy, which complicates things considerably. Justina, who is still an active member of the Old Colony church, and who has one child in school speaks in this excerpt. The other speakers include Neta, who has 5 children in school, Greta, who is no longer a part of the Old Colony Church, and Rita and Julie, who are the non-Old Colony leaders of the CAPC group.

Just before this excerpt, Justina, who has previously talked about how important it is for her to speak Low German with her children, points to the policy at the elementary school her children attend that forbids speaking languages other than English at school. She, like the other parents, had recently received a letter from the administration to tell children to refrain from speaking languages other than English at school. ${ }^{7}$ As a language and education researcher, when I first heard about the English-only rules that were being enforced at the two schools, I was horrified, as research has repeatedly shown that forbidding home languages in the school setting is detrimental to children's linguistic development (e.g., Blommaert \& van Avermaet, 2008; Cummins, 2013). It was especially alarming to me because the women and I had often spoken about how difficult it was to motivate their children to use Low German, and how complicated their feelings about this dilemma was.

It is worth noting the irony of the language policing in this context, since language use and community regulation of language use was one of the most significant factors in the decision to leave Canada in the first place. In their own parochial schools, the official language is Mennonite High German because the texts are in Mennonite High German, and colony school is so closely associated with the religious ("sindeosche", literally: "Sunday-like") realm. Officially, Low German is not intended to be a part of the school setting, although in practice, there is a tendency for both children and teacher to use Low German for a variety of reasons (Hedges, 1996; Sneath \& Fehr Kehler, 2016). The LGMs originally left Canada because they felt their right to educate their children was being encroached upon by Canadian lawmakers, and because of the close connection of schooling to church for this community, it was acutely felt as religious persecution, as has been previously discussed. This collective migration can be considered an act of civic engagement, a rejection of an entire political system, since the Old Colony Church leaders were concerned with maintaining a particular way of life free of government encroachment. It is the most extreme form of what Good Gingrich (2016) calls "selfimposed social exclusion." At the same time, individual actions of migrants returning to Canada can also be seen as acts of civic engagement, specifically civic disobedience, a way of contesting the English-dominant political system that LGMs sought to extract themselves from when they initially migrated. In the following excerpt, the speakers contest language norms of the broader Canadian context.

\footnotetext{
${ }^{7}$ The women in my study had their children at three different area schools, and two of the schools made similar rules about language use for similar reasons.
} 
Just preceding the following excerpt, Justina explicitly references Pennsylvania German (which is "like low german", line 001), the language spoken by the "other" Mennonites at her child's school, and about how "serious" they are about the children speaking Pennsylvania German at home, which has led to the conflict at the school.

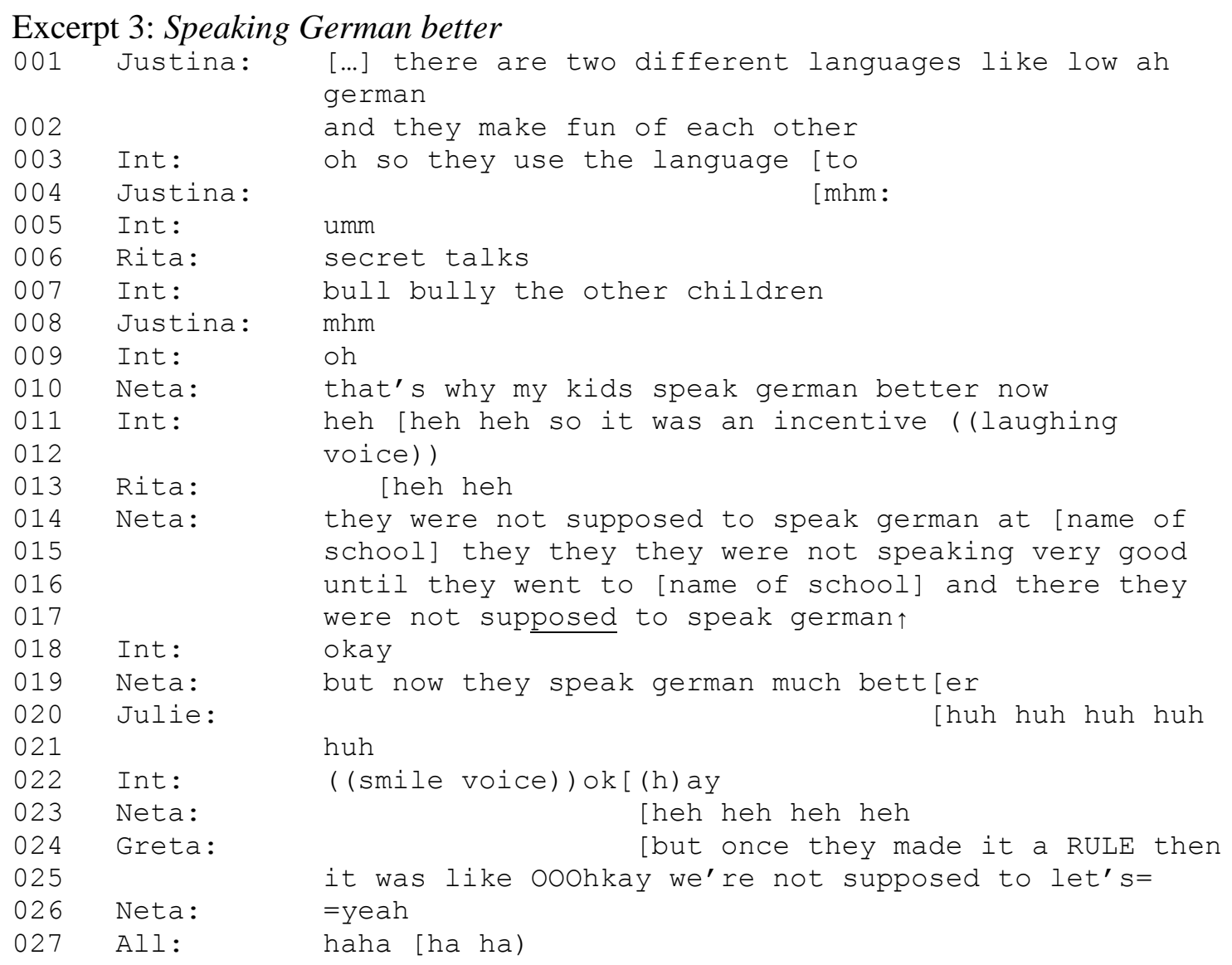

In the small story in this excerpt, Neta positions her children very differently than how she positioned herself in Excerpts 1 and 2. While she did not have much agency in her own school experience, and language was a mechanism that excluded her and rendered her voice- and powerless, she positions her children as actively employing language as a mechanism, delineating group membership and belonging in a subversive way, because she specifically mentions that the children's Low German proficiency improved once the school had expressly forbidden them to use it (lines 010; 014-016).

There is quite a bit of laughter in Excerpt 3, but it is worth noting that it is not group laughter. The people laughing in Excerpt 3 include the interviewer, Julie and Rita, the three people who are not connected to the LGM community through heritage. Neta presents the fact that her children now speak Low German better than they did before without a hint of laughter. She does not join in with the laughter until the very end of the excerpt, when Greta has reframed the story as typical "kid" behaviour in response to a rule (lines 024-025). For her and for Justina, the two mothers whose children attended schools where Low German was expressly forbidden, the edict seems to have initially elicited complicated emotions, since they were supposed to instruct their children to use 
English only in school. However, at home they were always working so hard to try to get them to stop using English and use Low German instead. The effect of these contrary home/school policies seems to have been that the children speak Low German both in and outside of school now, and with a higher proficiency level, at least according to their mothers.

Both Low German and Pennsylvania German are low status languages in Canada. While there are more print resources in Pennsylvania German than Low German, as well as a fair amount of academic research about it (cf: Schlegel, 2012), these resources are still fairly limited, and both Pennsylvania German and Low German can best be categorized as primarily oral languages. As a result, both languages are often characterized as dialects (although the speakers themselves refer to them as languages), a categorization which inherently devalues and reduces the languages. Research on the oral nature of many Indigenous languages in Canada has shown that Canada privileges print over oral culture in general, and the English language over other languages more specifically (cf. Hulan and Eigenbrod, 2008; Ricento, 2013). In other words, Pennsylvania German and Low German are not languages of power, until they bump up against one another in rural Ontarian schools, and then they are used to position speakers at the centre and periphery of Mennonite spaces (Giampapa, 2004). Then the languages become powerful tools of membership categorization and group delineation for the children who speak them, especially since most of the teachers and the administration of the schools do not speak the languages at all. The way the children use their languages also enables them to construct new civic identities for themselves, identities that include their home language as a valued and integral part.

Neta positions her children as linguistically flexible, being able to move fluidly between the languages in their linguascape. Her children do not experience the same voiceless- and powerlessness that she did when she was going to school. Neta positions her children as subverting the precise power dynamic that rendered her voiceless. English dominates the Canadian public school space-when Neta went to school, it was because she and her siblings were the only Low German speakers, and they couldn't speak or understand the space until they were able to do so in English. In the public school Neta's children attend, English is the dominant language because of official policy that intentionally marginalizes home languages. In fact, from the description of the school and the existence of the policy, there are more speakers of other language represented in the school than English monolinguals. Actively using Low German (or Pennsylvania German, for that matter), then, is a voicing act, a declaration of identity and self, and a way of constructing a new civic identity, establishing a place for their home language in an English-dominant Canadian space.

\section{Conclusions}

In her own stories, Neta positions herself as having little "agentive capacity" (Miller, 2010; 2012) in what happened to her in the Canadian school system as a result of her perceived lack of English language skills. On the other hand, she positions her children as having significant agentive capacity, highlighting how they intentionally use the languages at their disposal (especially Dietsch, their home language) to assert their own identity as LGMs in the public Canadian (school) space, thus contesting broader social processes and categories. Neta's stories about her own school experiences describe 
fear, confusion, and guilt. She positions herself as voiceless and powerless, with no effective intermediary who could help her make sense of her new reality in Canada. Her children, however, are positioned as reflective and adaptable managers of their linguistic and cultural repertoires. The stories she tells about her children are stories of confidence and assertion, of certainty in their own place in the world. What we are missing here, and points to additional research directions, are the voices of the children themselves - how they move within and through the spaces, how they experience being positioned, and how they position themselves, as children, as LGMs, as Canadians, as multilingual speakers. The children's use of Low German in the public school environment establishes school as a multilingual space, and Low German as a language of power. Using their home languages to contest English-dominant norms can be seen as an act of civic engagement, and this is the way Neta positions her children's linguistic behaviour, as well.

From an outsider's perspective, the various conservative Mennonite factions may appear the same, but the lived experience of these groups shows very little overlap in family or community life, except for the shared practice of enrolling their children in the public school environment. An important implication of the findings from this paper is that service providers and teachers must recognize the historical and sociocultural influences that have shaped these groups differently, and acknowledge the resources and linguistic and cultural flexibility children bring into their public school classrooms. In keeping with research by Cummins (2013) among others, there are ways of validating home languages in the classroom that are ultimately more productive for the development of student agentive capacity than banning the languages from the school space. Children are already constructing public school as a multilingual space-it is important for practitioners to recognize and validate home languages through a collaborative approach with children and families, rather than a punitive language ban.

The LGM children, as well as their conservative Mennonite counterparts, use language in the public school space as a way to assert their identities, contesting not only the dominant Canadian discourses about the value of oral vs. written language, but also contesting structures and value systems in their own cultures. This identity work plays out in the public school space in ways not intended and not anticipated by teachers and administrators at their schools. The civic identities constructed through these actions, and through the re-telling of these actions, enable LGM children and their parents to advocate for the validation of their home language, thus strengthening community ties. What results for these families who speak a primarily oral language in their homes is that their children seem to connect with the language and take ownership over the language and their use of their language in ways they had previously not done ${ }^{8}$. LGM children contest dominant discourses about themselves and their home languages in the public school space-paying attention to their efforts at civic engagement by more intentionally integrating and validating their home languages will not only benefit them, but also teachers and administrators working with them, as they learn more about the cultures of the students they teach, and the civic identities these children construct for themselves.

\footnotetext{
${ }^{8}$ The author gratefully acknowledges the support of the German-Canadian Studies Foundation that made this study possible.
} 


\section{References}

Bennett, E., Cordner, A., Taylor Klein, P., Savell, S., \& Baiocchi, G. (2013). Disavowing politics: Civic engagement in an era of political skepticism. Journal of American Sociology, 119 (2): 518-548.

Blommaert, J., \& P. Van Avermaet. (2008). Taal, Onderwijs en de samenleving. De kloof tussen beleid en realiteit. Berchem: EPO.

Bombardier, A.-L. (2016). The significance, meaning, and origins of distinctive Low German dress. Low German Networking Conference, Aylmer, Ontario, May.

Cox, C. (2013). The resilient word: Linguistic preservation and innovation among the Old Colony Mennonites in Latin America. Journal of Mennonite Studies, 31. pp. 50-74.

Cummins, J. (2013). "Language and Identity in Multilingual Schools: Constructing Evidence-based Instructional Policies.” In Managing Diversity in Education. Languages, Policies, Pedagogies, edited by D. Little, C. Leung, and P. Van Avermaet, 3-26. Bristol: Multilingual Matters.

Delli, M. (2016). Civic engagement. APA.Org. American Psychological Association.

Georgakoupoulou, A. (2007). Small stories, interaction and identity. Amsterdam: John Benjamins.

Giampapa, F. (2004). The politics of identity, representation, and the discourses of selfidentification: Negotiating the periphery and the centre. In A. Pavlenko, \& A. Blackledge (Eds.), Negotiation of identities in multilingual contexts. (pp. 192218). Clevedon: Multilingual Matters.

Good Gingrich, Luann (2016). Out of place: Social exclusion and Mennonite migrants in Canada. Toronto: University of Toronto Press.

Harré, R. \& van Langenhove, L. (1991). Varieties of positioning. Journal for the Theory of Social Behaviour 21, 393-407.

Hedges, K. L. (1996). "Plautdietsch” and "Huuchdietsch” in Chihuahua: Language literacy and identity among the Old Colony Mennonites in Northern Mexico. (Unpublished doctoral dissertation.) Yale University.

Hulan, R. \& Eigenbrod, R. (2008). Aboriginal oral traditions: Theory, practice, ethics. Halifax: Fernweh Publishing.

Jefferson, G. (2004). Glossary of transcript symbols with an introduction. In G. H. Lerner (Ed). Conversation Analysis: Studies from the First Generation. (pp: 13-31). Amsterdam: John Benjamins.

Kampen Robinson, C. (2017). Contesting the centre: Low German-speaking Mennonite language, literacy, and identity constructions. (Unpublished doctoral dissertation.) University of Waterloo.

Krahn, C. \& Sawatzky, H. L. (1990). Old Colony Mennonites. Global Anabaptist Mennonite Encyclopedia Online. Retrieved 2 August 2016, from http://gameo.org/index.php?title=Old_Colony_Mennonites\&oldid=113570.

Loewen, R. (2013). Village among nations: "Canadian” Mennonites in a transnational world, 1916-2006. Toronto: University of Toronto Press.

Ricento, T. (2013). The consequences of official bilingualism on the status and perception of non-official languages in Canada. Journal of Multilingual and Multicultural Development, 34(5), 475-489. 
Rumbaut, R. G. (2002). Severed or sustained attachments? Language, identity and imagined communities in post-immigrant generations. In P. Levitt \& M.C. Waters (Eds.), The changing face of home: The transnational lives of the second generation (p. 43-95). New York: Russell Sage Foundation.

Schegloff, E. A., Jefferson, G., \& Sacks, H. (1977). The preference for self-correction in the organization of repair in conversation. Language 53(2), 361-382.

Schlegel, J. (2012). Orthography in practice: A Pennsylvania German case study. In A. Jaffe, J. Androutsopoulos, M. Sebba, \& S. Johnson (Eds.) Orthography as social action: Scripts, spelling, identity and power. (p. 177-202). Boston: De Gruyter.

Smith, C. H. (1981). Smith's Story of the Mennonites (5th ed.). Newton, Kansas: Faith and Life Press.

Sneath, R. \& Fehr Kehler, T. (2016). An alternative type of citizen: Schooling for Low German Mennonite girls. Still/Moving: Stories of Dietsche women. London, Ontario.

Steiner, S. (2015). In search of promised lands: A religious history of Mennonites in Ontario. Kitchener-Waterloo: Herald Press.

\section{Author Biography}

Christine Kampen Robinson completed her $\mathrm{PhD}$ in Applied Linguistics and German at the University of Waterloo. Her research interests centre on the role language plays in how we think about and talk about ourselves, especially in contexts of multilingualism and migration. An interactional sociolinguist, she is especially interested in how different languages and different literacies give people access to different spaces and ways of being, and how individuals contest and reinvent both these spaces and available positions. 